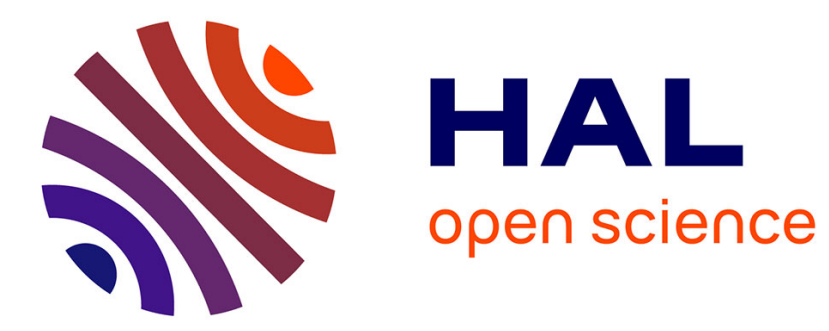

\title{
Microstructure effect on the HNO3-HF etching of LPCVD boron-doped polycrystalline silicon
}

\author{
F. Mansour-Bahloul, D. Bielle-Daspet, A. Peyrelavigne
}

\section{To cite this version:}

F. Mansour-Bahloul, D. Bielle-Daspet, A. Peyrelavigne. Microstructure effect on the HNO3-HF etching of LPCVD boron-doped polycrystalline silicon. Revue de Physique Appliquée, 1987, 22 (7), pp.671-676. 10.1051/rphysap:01987002207067100 . jpa-00245595

\section{HAL Id: jpa-00245595 https://hal.science/jpa-00245595}

Submitted on 1 Jan 1987

HAL is a multi-disciplinary open access archive for the deposit and dissemination of scientific research documents, whether they are published or not. The documents may come from teaching and research institutions in France or abroad, or from public or private research centers.
L'archive ouverte pluridisciplinaire HAL, est destinée au dépôt et à la diffusion de documents scientifiques de niveau recherche, publiés ou non, émanant des établissements d'enseignement et de recherche français ou étrangers, des laboratoires publics ou privés. 
Classification

Physics Abstracts

$81.00-81.60$

\title{
Microstructure effect on the $\mathrm{HNO}_{3}-\mathrm{HF}$ etching of LPCVD boron-doped polycrystalline silicon
}

\author{
F. Mansour-Bahloul, D. Bielle-Daspet and A. Peyrelavigne (*) \\ L.A.A.S. du C.N.R.S., 7, avenue C.-Roche, 31077 Toulouse, France \\ (Reçu le 6 octobre 1986, révisé le 16 mars 1987, accepté le 9 avril 1987)
}

\begin{abstract}
Résumé. - Le taux d'attaque par la solution $50 \mathrm{HNO}_{3}(70 \%)-1 \mathrm{HF}$ (49\%) non diluée est étudié, sous différentes conditions de température $\left(0\right.$ à $\left.45^{\circ} \mathrm{C}\right)$ et d'agitation de la solution, pour trois séries de couches de $\mathrm{Si}$ LPCVD d'épaisseur $w \approx 0,6 \mu \mathrm{m}$, déposées à 570 ou $620^{\circ} \mathrm{C}$ sur des substrats préalablement oxydés, et dopées in situ à $10^{20}$ ou $10^{17} \mathrm{~cm}^{-3}$. Les résultats sont comparés aux variations de microstructure obtenues, en fonction de la profondeur et de la série des dépôts, à l'aide de caractérisations par TEM, RHEED, spectrométrie Raman et Réflectrométrie UV. L'étude montre que les variations du taux d'attaque des films de $\mathrm{Si}$ polycristallin dopés bore, suivant leur profondeur ou leurs conditions de dépôt, sont dues au changement (du transfert-de-masse pour la réaction-de-surface) de l'étape qui contrôle la vitesse du processus chimique, ceci par suite de la contribution accrue de la réaction d'oxydation de surface se produisant au niveau des joints de grains.
\end{abstract}

\begin{abstract}
The etching rate of the $50 \mathrm{HNO}_{3}(70 \%)-1 \mathrm{HF}(49 \%)$ undiluted solution was studied, for various conditions of etching-bath temperature $\left(0\right.$ to $\left.45^{\circ} \mathrm{C}\right)$ and agitation, for three series of LPCVD Si layers $w \approx 0.6 \mu \mathrm{m}$ thick, deposited on oxidized Si wafers at 570 or $620^{\circ} \mathrm{C}$, and with in situ boron doping at $10^{20}$ or $10^{17} \mathrm{~cm}^{-3}$. The results were compared with the changes in the layer microstructure with layer series and depth $Z$ obtained from TEM observations, RHEED patterns, Raman spectrometry and UV Reflectrometry. They evidence that the changes in the etching rate of polycrystalline Si films with film depth and deposition conditions are due to the changes in the rate-controlling-step of the etching process (from mass-transfer to surface-reaction) because of the enhanced contribution of the surface-reaction of oxidation at the $\mathrm{Si}$ grain boundaries.
\end{abstract}

\section{Introduction.}

Polycrystalline silicon (p-Si) is more and more used for a number of purposes in the fabrication of electronic devices (FET gate, emitter of bipolar transistors, dopant source...). Thus much is certain, the $\mathrm{p}-\mathrm{Si}$ electrical properties and the processes for $\mathrm{p}$ Si film doping, oxidation and engraving or etching will have to be controlled at the best. Consequèntly, number of recent literature works have been devoted to the understanding of the structural or electrical properties of the p-Si layers [1-8] and to their oxidation features $[9,10]$. On the other hand, in spite of the various technological applications where

(*) Motorola Semiconducteurs S.A., avenue GénéralEisenhower, 31023 Toulouse, France. wet etching may suffice, only few studies of the wet p-Si etching have been reported [11]. In the present work, we then aimed to set up the correlations between structural and chemical properties which rule out the wet-etching behaviour of p-Si films obtained by chemical vapour deposition. The study dealt with as-grown polycrystalline LPCVD layers of $\approx 0.6 \mu \mathrm{m}$ thickness, with in situ boron doping of $10^{20}$ or $10^{17} \mathrm{~cm}^{-3}$, deposited at 570 and $620^{\circ} \mathrm{C}$. The microstructure of these films had been investigated as a function of layer depth by using correlated characterization techniques; the results have been described in a previous paper [8]. In the following, the film chemical etching (as a function of layer depth) by $\mathrm{HNO}_{3}$ rich solutions of the $\mathrm{HNO}_{3}-\mathrm{HF}$ system was studied for different hydrodynamic conditions and in the temperature range 0 to $45^{\circ} \mathrm{C}$. Indeed, from this set of chemical conditions and 
Arrhenius rules, it may be stated clearly if the etching process of the silicon samples is dominated by the chemical reaction at the sample surface or by the mass-transfer of the reagent to the sample. We will show here that one or the other of these two steps of the etching process can control the etching of polycrystalline deposits because of the changes in the $\mathrm{p}-\mathrm{Si}$ microstructure with film depth and deposition conditions.

\section{Sample microstructure and chemical etching con- ditions.}

Three series (A, B, C) of polycristalline layers, 0.55 to $0.6 \mu \mathrm{m}$ thick, were deposited on thermally oxidized $\mathrm{Si}$ wafers in the LPCVD system at Motorola (Toulouse, France) at 570 (A series) or $620^{\circ} \mathrm{C}$ (B and $\mathrm{C}$ series). The in situ boron doping was about $10^{20}$ ( $\mathrm{A}$ and $\mathrm{B}$ series) or $10^{17} \mathrm{~cm}^{-3}$ (C series). Previous works, detailed in references [7,8], had been devoted to the characterization of the microstructure of these samples : structural properties and texture had been obtained from Transmission Electron Microscopy observations on cross-sections and Reflected High Energy Electron Diffraction patterns ; Raman spectrometry at $\backslash=488 \mathrm{~nm}$ and measurements of the UV Absolute Reflectance $(\backslash=250$ to $600 \mathrm{~nm})$ had been specially used for the inspection of the crystalline state and «quality » of the deposits (i.e., Raman grain size, material density deficit $v_{\mathrm{vf}} \ldots$ which point to material twins, voids or defects... [8]) ; flatness of the sample surface had been monitored by measuring the optical and mechanical surface roughnesses $\sigma_{\mathrm{o}, \mathrm{m}}$. Both asgrown and etched samples had then been investigated.

The characteristics and microstructure of the A, B and $C$ deposits are summarized in figure 1 . These three film series are polycrystalline, with mean $\mathrm{Si}$ grain size (in a plane parallel to the $\mathrm{p}-\mathrm{Si} / \mathrm{SiO}_{2}$ interface) of about $1200 \AA$ at the external surface. But changes in the layer microstructure with film boron content $N_{\mathrm{B}}$ and deposition temperature Td are observed. Furthermore, in the three film series, the material crystallinity varies within the layer depth $Z$ : the polycrystalline state with a columnar character and $\langle 110\rangle$ texture (cf. $Z_{1}$ and $Z_{2}$ regions in the scheme of Fig. 1) always appear above a 500 to $1000 \AA$ thick region $\left(Z_{3}\right)$ of randomly oriented grains $\leqslant 100 \AA$ in size, located near the $\mathrm{pSi} / \mathrm{SiO}_{2}$ interface. In the $Z_{1}(Z=0$ to $\approx 1000 \AA)$ and $Z_{2}$ regions, the columnar character and the $\langle 110\rangle$ texture increase with increasing $N_{\mathrm{B}}$ and $T_{\mathrm{d}}$. However, in these regions, the crystalline «quality " of the film material - as described by the Raman peak frequency $(w)$ and half-height-width $(\Gamma)$ and the UV Absolute Reflectance [8] - evidences further variations of the deposit microstructure. In the deep
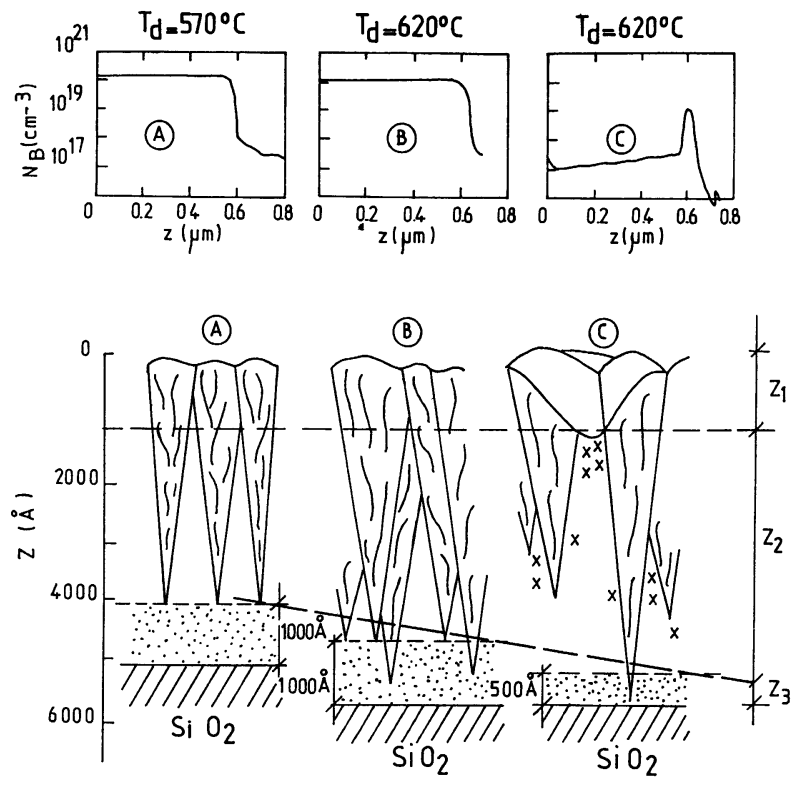

Fig. 1. - A, B, C deposit series : (a) Boron concentrations measured by Secondary Ion Mass Spectroscopy; (b) Schematic representation of the deposit microstructure deduced from characterisations by TEM, RHEED, Raman Spectrometry and UV Reflectrometry.

region $Z_{2}$ the crystalline «quality " appears increased by the deposition temperature $\mathrm{Td}$ and decreased by the boron doping $N_{\mathrm{B}}$. This crystalline "quality" is especially higher in the near-surface region $Z_{1}$ than in the deep region $Z_{2}$ for the two $A$ and $B$ series with the highest boron content. It had been also noticed that the surface roughness of the as-grown deposits simultaneously increases when the «quality » of the $Z_{1}$ region increases; the surface roughness then is especially high in the as-grown films of the $\mathrm{C}$ series.

Present work was focused on the effect of the LPCVD layer microstructure on the etching by the undiluted solution $\mathrm{HNO}_{3}$ (70\%)-HF (49\%) with volume ratio 50/1 which belongs to the $\mathrm{HNO}_{3}$ rich case of the $\mathrm{HNO}_{3}$ - $\mathrm{HF}$ systems.

For many years, the etching of silicon by the $\mathrm{HNO}_{3}$ - $\mathrm{HF}$ based systems is known to proceed by the following oxidation-followed-dissolution process $[12,13]$ :

$$
\begin{array}{ll}
\text { (a) } 3 \mathrm{Si}+4 \mathrm{HNO}_{3} & 3 \mathrm{SiO}_{2}+4 \mathrm{NO}+2 \mathrm{H}_{2} \mathrm{O} \\
\text { (b) } \mathrm{SiO}_{2}+6 \mathrm{HF} & \mathrm{H}_{2} \mathrm{SiF}_{6}+\mathrm{H}_{2} \mathrm{O}
\end{array}
$$$$
\text { (dissolution) }
$$

The etching process is controlled by the slowest of the reactions (a) (b) and may thus vary with the etching conditions and the sample properties. For example, consider the reaction (b) which belongs to the quasi-instantaneous dissolution of the formed $\mathrm{SiO}_{2}$. When the etching conditions are such that (b) 
becomes the rate-controlling-step of the process (usual case of the etching of polished monocrystalline wafers with solution composition where HF is in limited supply), the mass-transfer which corresponds to the diffusion of the fluoride species to the sample material surface is the dominant factor : the etching rate is ruled out by the hydrodynamic parameters of the experiment (etching bath agitation, sample surface roughness) and its activation energy is that of the diffusion of the HF species through the solution [12]. On the contrary, in those conditions where the oxidation reaction (a) is the rate-limiting-step (e.g., etching of polished wafers in HF rich solutions), the sample or etch bath capabilities for oxidation becomes of major importance : the etching rate increases with the amounts, at the sample surface, of the sample electronic dangling bonds (i.e., with surface crystalline orientation, doping or defects) and oxidizing species from the bath.

Figure 2 shows the location of the $50 \mathrm{HNO}_{3}$ (70 \%)-1 HF (49\%) undiluted solution on the well known iso-etch-contours of the $\mathrm{HNO}_{3}-\mathrm{HF}-\mathrm{H}_{2} \mathrm{O}$ systems applied to monocrystalline silicon [13]. In order to evidence how the microstructure of the LPCVD layers may affect the etching process, the measurement procedure of the present work was centred on the study of the variations of the etched thickness $Z$ with etching time $t$ of the A, B and C films

- (i) by comparison with the etching behaviour $Z(t)$ of boron-doped monocrystalline samples of $\langle 100\rangle$ or $\langle 111\rangle$ orientation and 0.01 to $10 \Omega \mathrm{cm}$ resistivity,

- and (ii) as a function of agitation and temperature of the etching solution. 0 to $45^{\circ} \mathrm{C}$ thermostated baths and manual or magnetic (400 to $1000 \mathrm{t} / \mathrm{min}$ )

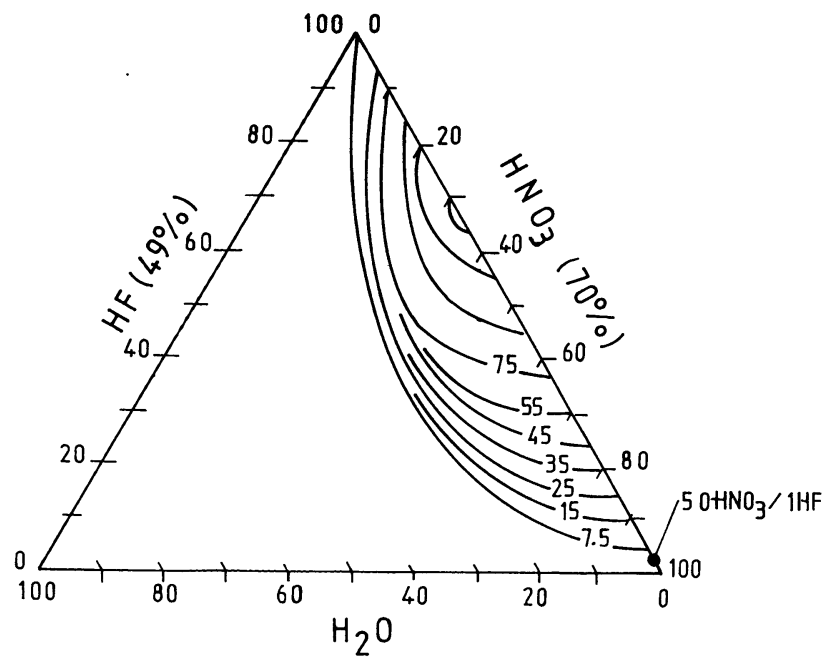

Fig. 2. - Location of the $50 \mathrm{HNO}_{3}(70 \%)-1 \mathrm{HF}(49 \%)$ un-diluted solution on the iso-etch-contours of the $\mathrm{HNO}_{3}-\mathrm{HF}-\mathrm{H}_{2} \mathrm{O}$ systems applied to monocrystalline silicon (from Ref. [12]). agitations were used. In any cases, the etching solution was prepared in sufficient amount to give the several baths necessary for the compared study of $Z(t) v s$. layer series $\mathrm{A}, \mathrm{B}, \mathrm{C}$, temperature $T \ldots$... Before etching, the samples were partly covered by Apiezon wax and carefully cleaned and desoxidized. Etching was stopped by immersing the samples in desionized water. The etched depths $Z$ were measured by using a stylus surface profilometer.

\section{Results and discussion.}

The behaviour, around room temperature, of the etching rate of the $\mathrm{A}, \mathrm{B}, \mathrm{C}$ layer samples is illustrated in figures 3 and 4 . For the etching solution used which gives only small changes in the monocrystalline silicon etching rate with crystal orientation and boron doping (cf. Figs. 3a and 4), the present pSi etching results indicate what follows :

1) As shown by the changes in the variation $Z(t)$ of the etched depth $Z$ with time $t$ (cf. Fig. 3), the etching behaviour of the polycrystalline samples both varies according to the film deposition conditions and the etching temperature. Moreover, (i) the $Z(t)$ variation of the films departs from the $Z(t)$ linear feature which is typical of the monocrystalline silicon material, and (ii) the changes in the
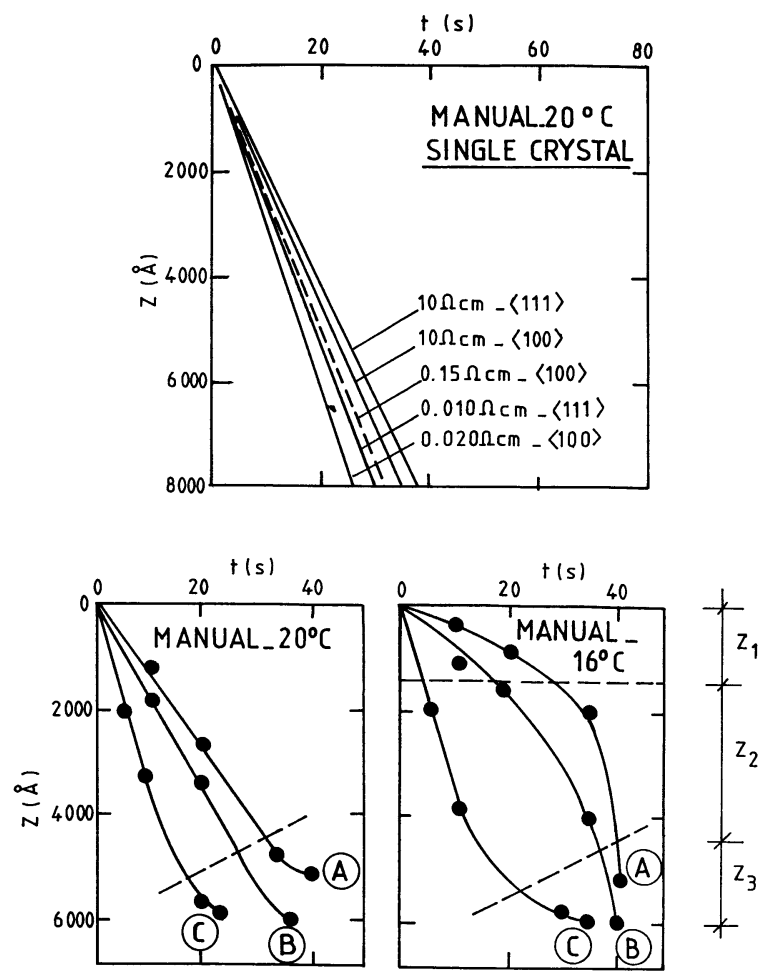

Fig. 3. - Etching by the un-diluted solution $50 \mathrm{HNO}_{3}$ (70\%)-1 HF (49\%). Variations of the etched depth $Z$ with etching time $t$ for at 16 or $20^{\circ} \mathrm{C}$ for : (a) monocrystalline sample materials, (b) polycrystalline samples of the $\mathrm{A}, \mathrm{B}, \mathrm{C}$ deposit series. 
etching rate $\Delta Z / \Delta t$ with the film depth $Z$ appear clearly reminiscent of the $Z_{1,2,3}$ regions previously evidenced [8] by the layer microstructure studies (cf. Fig. 1). (For insuring this analogy, we first verified that the same values of the etched depth $Z(t)$ are obtained by using either one etching step of duration $t$ or two steps of duration $t^{\prime}$ and $t^{\prime \prime}$ with $t^{\prime}+t^{\prime \prime}=t$. SIMS measurements were also used to control that no noticeable changes in the boron concentration were produced at the surface of the etched samples.)

2) Clear differences appear in the values of the mean etching rates $\Delta Z / \Delta t$ measured for the $Z_{1}\left(t_{1} \leqslant 10-15 \mathrm{~s}\right)$ and $Z_{2}\left(t_{2} \approx 30-40 \mathrm{~s}\right)$ regions of the layer samples as well as in the variations of these rates when the etching bath agitation is increased. As shown by the results reported in table I and figure 4 :

(i) Only the near-surface region $\mathrm{Z}_{1}$ of the $\mathrm{C}$ series film with the lowest boron content $N_{\mathrm{B}} \approx 10^{17} \mathrm{~cm}^{-3}$

Table I. - Etching behaviour of the A B C series samples, at $20^{\circ} \mathrm{C}$; etching rate under manual agitation, changes in the etching rate due to solution agitation: measured (cf. Fig. 4) and expected (cf. monocrystalline silicon case) features.

\begin{tabular}{lcccc}
\hline & \multicolumn{2}{c}{ Film } & Etching & \multicolumn{2}{c}{ Etching behaviour } \\
& region & $(\AA / \mathrm{s})$ & measured & expected \\
$\mathrm{A}\left[570{ }^{\circ} \mathrm{C}-10^{20}\right]$ & $\mathrm{Z}_{1}$ & -120 & increase & $\uparrow$ \\
& $\mathrm{Z}_{2}$ & 85 & decrease & $\uparrow$ \\
$\mathrm{B}\left[60^{\circ} \mathrm{C}-10^{20}\right]$ & $\mathrm{Z}_{1}$ & 130 & increase & $\uparrow$ \\
& $\mathrm{Z}_{2}$ & 150 & decrease & $\uparrow$ \\
$\mathrm{C}\left[620^{\circ} \mathrm{C}-10^{17}\right]$ & $\mathrm{Z}_{1}$ & 400 & small increase & $\uparrow$ \\
& $\mathrm{Z}_{2}$ & 200 & decrease & $\uparrow$ \\
\hline
\end{tabular}
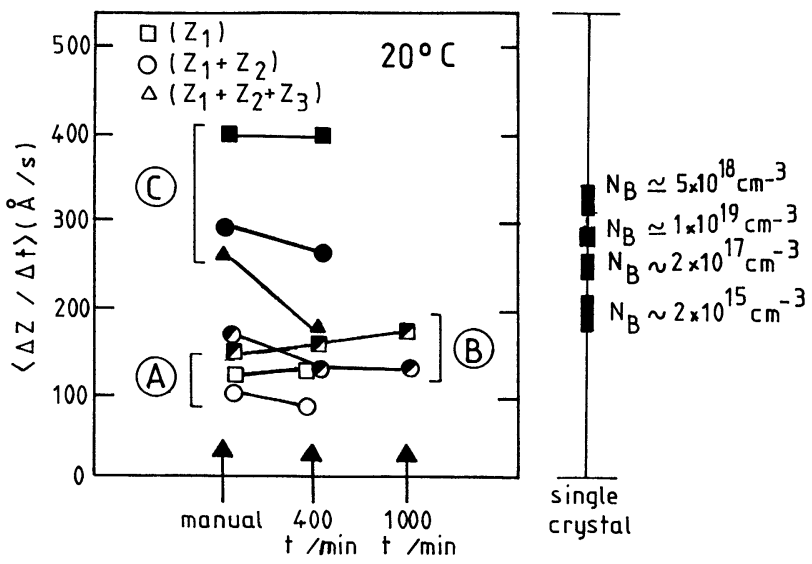

Fig. 4. - Effect of agitation of the $50 \mathrm{HNO}_{3}(70 \%)-1 \mathrm{HF}$ (49\%) solution on the mean etching rate $\langle\Delta Z / \Delta t\rangle$ of the $Z_{1}, Z_{1}+Z_{2}$ and $Z_{1}+Z_{2}+Z_{3}$ regions of the $A, B, C$ deposits schematized in figure 1 . shows a clearly higher etching rate than the $10^{15}$ to $10^{19} \mathrm{~cm}^{-3}$ doped samples of monocrystalline silicon. In the $\mathrm{A}$ and $\mathrm{B}$ series with the highest boron content $N_{\mathrm{B}} \approx 10^{20} \mathrm{~cm}^{-3}$, the etching rates of the $\mathrm{Z}_{1}$ and $Z_{2}$ regions are very low. But note that the measured etching rates of the $Z_{1}$ regions are usually higher than the ones of the deep regions $Z_{2}$.

(ii) When increasing the etching bath agitation, only the etching rates of the near-surface regions $Z_{1}$ tend to increase (cf. Fig. 4). Thus, when varying the etching hydrodynamic conditions, only the nearsurface regions $Z_{1}$ of the $A, B, C$ deposits show the classical silicon etching feature due to mass-transfer. On the contrary, the etching rates associated with the layer deep regions $Z_{2}$ always decrease with increasing agitation. Thus, the $Z_{2}$ etching rates behave as governed by the chemical surface-reaction instead of the previous diffusion phenomena (cf. $\S 2$ ). (We remark that an even stronger decrease in the etching rates should characterize the etching of the near-interface regions $Z_{3}$ with crystalline grains of very small size. But these regions were hard to study in present work).

The above etching behaviours are sustained by the variations of the etching rates with etching bath temperature $T$ shown by the Arrhenius plot in figure 5 (B sample case). The etching rates of the $\mathrm{Z}_{1}$ and $\mathrm{Z}_{2}$ regions again set out strong dissimilar features. For $Z_{1}$, the etching rate has an activation energy $E_{\mathrm{al}}$

$$
\Delta Z / \Delta t(t=15 \mathrm{~s})=a_{1} \exp -\left(E_{\mathrm{a} 1} / k T\right)
$$

whose value of $0.16 \mathrm{eV}$ totally agrees with the activation energy $E_{\mathrm{ac}}$ which characterizes etching of monocrystalline samples when the mass-transfer of the HF species (cf. \& 2) is the limiting step of the etching process [12]. On the other hand, in the $\mathrm{Z}_{2}$ region, the activation energy $E_{\mathrm{a} 2}$ is zero. This value implies that the rate-limiting-step of the etching process now behaves like the surface reaction (a)

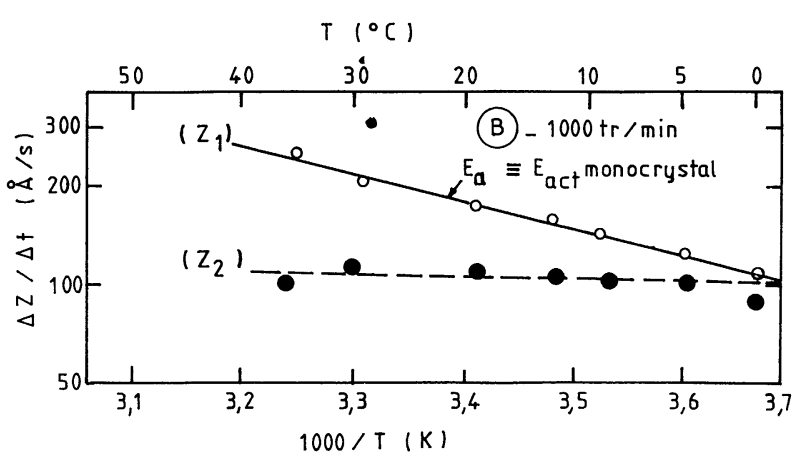

Fig. 5. - Arrhenius plot of the variation of the etching rates of the $Z_{1}$ and $Z_{2}$ regions of the $B$ series samples with etching temperature $T$ (solution agitation of $1000 \mathrm{t} / \mathrm{min}$ ). 
does when it occurs at a «quasi-infinite » sample surface $[14,15]$.

On the whole, the study thus put into evidence that systematic difference in the etching behaviours exists between monocrystalline and $\mathrm{p}$-Si film samples and between the $\mathrm{A}, \mathrm{B}$ and $\mathrm{C}$ series of the borondoped deposits. Furthermore, whatever the agitation and temperature of the etching bath, the etching features of the A, B, C deposit series appear ruled out by the structural properties of the films :

- Like for monocrystalline silicon, in the nearsurface regions $Z_{1}(Z \leqslant 500-1500 \AA)$ of the $\mathrm{A}, \mathrm{B}, \mathrm{C}$ series where the deposited material tends to be of the largest $\mathrm{Si}$ grains and the highest crystalline " quality », etching by the $\mathrm{HNO}_{3}$ rich solution corresponds to a process thermally activated by the $\mathrm{SiO}_{2}$ dissolution (i.e., by mass-transfer of the $\mathrm{HF}$ species), whose rate increases with increasing agitation of the etching bath. The etching rate is also specially high in the $\mathrm{C}$ series with the largest surface roughness but lowest boron content. The etching rates of the very highly doped samples of the $A$ and $B$ series are much lower, in agreement with the known effect of very high boron content on the $\mathrm{SiO}_{2}$ dissolution.

- On the contrary, in the deep regions $Z_{2}$, etching is controlled by a thermally un-activated reaction whose rate first decreases with increasing bath agitation and second is less sensitive to the boron content of the sample. This implies that the rate-controlling-step of the etching process is now the surface-reaction (i.e., oxidation) of an infinite surface. It thus means that etching of the $\mathrm{Z}_{2}$ region is ruled out by the oxidation reaction at the grain boundaries of the polycrystalline deposits.

Comparison of structural and chemical properties of the $Z_{1,2}$ regions of the $A, B, C$ series films is drawn in figures 6-7. Results in figure 6 show the

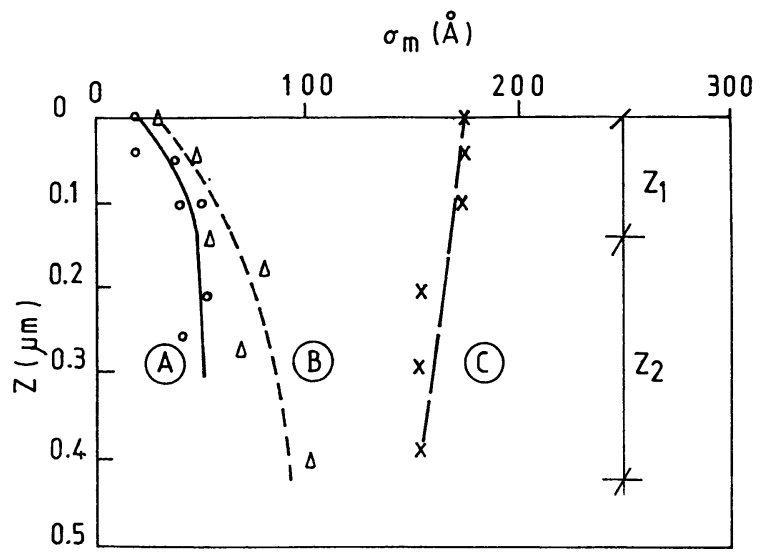

Fig. 6. - Mechanical roughness $\sigma_{m}$ of as grown and etched samples of the $A, B, C$ series : variation with etched depth $Z$.
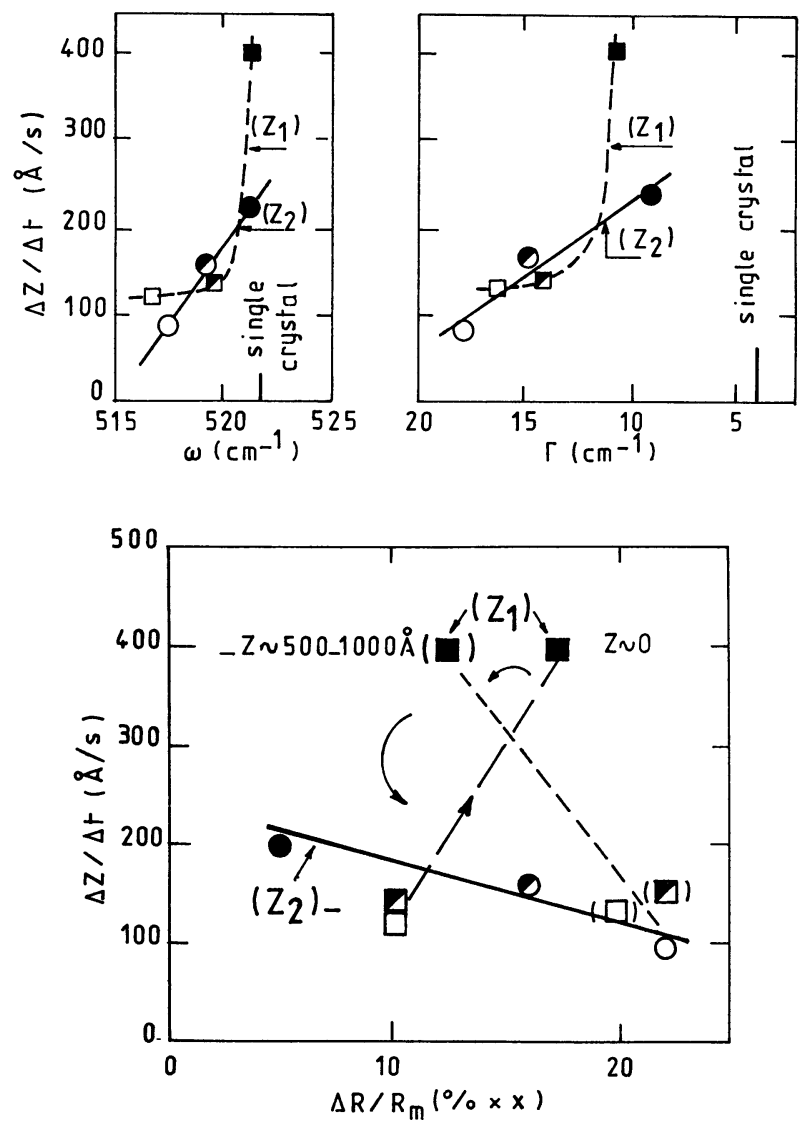

Fig. 7. - Comparison of the etching rates in the $Z_{1}$ and $Z_{2}$ regions of the $A, B, C$ deposits with : 7-a the frequency $\omega$ and half-height-width $\Gamma$ of the Raman Si line, 7-b the relative value of the decrease of the Absolute UV Reflectance in the light-wavelength range $280(x \leq 2)$ to $450 \mathrm{~nm}(x=1)$.

changes in the surface roughness $\sigma_{\mathrm{m}}$ of $\mathrm{A}, \mathrm{B}, \mathrm{C}$ samples with etched depth $Z$ ( $\approx 20^{\circ} \mathrm{C}$, manual) : in the $\mathrm{C}$ series deposits, with high roughness of the asgrown surface, the high etching rate of the $Z_{1}$ region flattens the Si crystallites and leads to the decreased roughness of the etched samples; in the $A$ and $B$ series deposits, with the lowest values of the roughness of the as-grown surface and etching rate of the $Z_{1}$ region, the grain-boundary contribution to the $Z_{2}$ region etching is responsible for the increased roughness of the deeply etched samples.

In figure 7 , the $20^{\circ} \mathrm{C}$ etching rates of the nearsurface $Z_{1}$ and deep $Z_{2}$ regions are compared with the values, measured on the as-grown $(Z=0)$ and etched samples of the three studied deposit series, of the Raman peak frequency $w$ or width $\Gamma$ and relative decrease $\Delta R(\backslash) / R_{\mathrm{m}}(\backslash)$ of the difference $\Delta R(/)$ between the UV Absolute Reflectance $R_{\mathrm{m}}(\backslash)$ of a monocrystalline sample and the film sample one $R(\backslash)$. As discussed elsewhere [8], these Raman and Reflectance parameters indicate ((within the penetrating depth of the used light wavelength)) the size 
(w) and size distribution $(\Gamma)$ of $\mathrm{Si}$ crystal with defect-free lattice, and the deficit density - or excess volume - associated with the material defects (twins, dislocations, vacancies...). As shown by the results in figure 7 , only the etching rate of the $\mathrm{Z}_{2}$ regions continuously decreases with decreasing Raman and UV Reflectance quality of the $\mathrm{Z}_{2}$ polycrystalline region with columnar character.

\section{Conclusion.}

The study puts into evidence the existence of three regions with different chemical reactivity in borondoped polycrystalline films of around $0.6 \mu \mathrm{m}$ thickness deposited at 570 and $620^{\circ} \mathrm{C}$. These regions are confirmed by the studies of the layer microstructure using TEM, Raman and Absolute Reflectance results. Especially the two regions above the interfacial one have been investigated.

The $Z_{1}(Z=0$ to $\approx 1000 \AA)$ region near the external surface of the boron-doped deposits shows chemical properties close to the monocrystalline silicon ones. It then appears as a polycrystalline material whose major chemical properties are dominated by the crystalline grains. Beneath the $Z_{1}$ region exists a region $Z_{2}(Z \approx 1000$ to $4-5000 \AA)$ whose properties strongly differ from those of monocrystalline silicon. Its etching rate has a null value of the activation energy; the etching hydrodynamical properties obey the rules of surface reactions and no more the mass transfer ones. This region appears dominated by the surface-reaction of oxidation with a quasi-infinite surface effect.

From TEM observations, Raman Spectrometry and UV Reflectrometry, the above etching behaviour agrees with the changes in the microstructure of the p-Si films studied with film depth and deposition conditions. The highest surface roughness and lowest $10^{17} \mathrm{~cm}^{-3}$ boron content of the $\mathrm{C}$ series films (deposited at $620^{\circ} \mathrm{C}$ ) agree with the highest etching rate of their $Z_{1}$ region. In the deep regions $Z_{2}$ of the three deposit series studied, the crossing down of the columnar grains takes into account the decreased values of the etching rate due to the large increase of the silicon developed surface and the prevailing effect of the grain boundaries. Thus, as previously observed for the crystalline « quality » of $Z_{2}$ region [8], the etching rate of the $Z_{2}$ region now decreases with decreasing the film boron content and deposition temperature.

\section{Acknowledgments.}

We wish to express our acknowledgments to F. Rossel of LAAS for her technical assistance and to P. Bernoux, of Motorola, for his help in preparing the films.

\section{References}

[1] SARASWAT, K. C., in Grain boundaries in semiconductors, Pike/Seager Ed. (Elsevier Science Pub. Co.) 1982 , p. 261.

[2] Lu, N. C. C., LU, C. Y., LeE, M. K., Shih, C. C., WANG, C. S., ReUTER, W. and SHENG, T. T., J. Electrochem. Soc. 131 (1984) 897.

[3] Meyerson, B. S. and Olbricht, W., J. Electrochem. Soc. 131 (1984) 2361.

[4] Harbeke, G., Proc. Int. School Polycrystalline Semiconductors, Erice Maly, Ed. by G. Harbeke (Springer Series) 57 (1985) p. 156

[5] Bisaron, R., Magarino, J. and Proust, N., J. Appl. Phys. 59 (1986) 1167.

[6] Brokman, A., Gat, R. and Alpern, Y., Appl. Phys. Lett. 49 (1986) 382.

[7] Mansour-Bahloul, F., Thesis Univ., P. Sabatier, Toulouse, France, July 1986.

[8] Bielle-Daspet, D., Mansour-Bahloul, F., Martinez, A., Pieraggi, B., David, M. J., De
Mauduit, B., Oustry, A., Carles, R., AjustRON, F., MAZL, A. and Riboulet, P., to be published in Thin Solid Films 150 (1987).

[9] Groeseneken, G. and Maes, H., IEEE Trans. El. Dev. ED-33 (1986) 1028.

[10] Lu, C. Y. and Tsai, N. S., J. Appl. Phys. 59 (1986) 3574.

[11] FelCh, S. B. and Sonico, J. S., Solid State Techn. (1986) 70.

[12] Schwartz, B. and Robiins, H., J. Electrochem. Soc. 108 (1961) 365.

[13] Schwartz, B. and RobBins, H., J. Electrochem. Soc. 123 (1976) 1903.

[14] LAWLESS, K. R., Physics of thin films, advances in research and development, Ed. by G. Huss and R. E. Thun (Academic Press N. Y.) vol. 4 (1967)

[15] Landau, L. D. and Lifschitz, E. M., Fluid mechanics (Pergamon Press Oxford) p. 241 (1959). 